\title{
Antimelanoma activity of perphenazine and prochlorperazine in human COLO829 and C32 cell lines
}

\author{
Michał Otręba ${ }^{1}$ (D) Monika Pajor $^{1}$ - Jared D. Warncke ${ }^{2}$ \\ Received: 7 March 2019 / Accepted: 16 May 2019 / Published online: 6 June 2019 \\ (C) The Author(s) 2019
}

\begin{abstract}
Cutaneous melanoma is least common (only about $1 \%$ of skin cancers) but is the deadliest malignant tumor. Moreover, amelanotic types of melanoma are very difficult for clinical diagnosis. The standard therapy can cause a lot of side effects, e.g., nausea, vomiting, and headaches, which means that novel and effective strategies are required. Interestingly, phenothiazine derivatives possess sedative, antiemetic, and anticancer activity. Our goal was to determine the effect of perphenazine and prochlorperazine on cell viability, motility, microphthalmia-associated transcription factor (MITF) and tyrosinase content in melanotic and amelanotic melanoma cells. The viability of C32 and COLO829 melanoma cells was evaluated by the WST-1 colorimetric assay; impact on motility of human melanoma was performed by wound-healing assay, while tyrosinase and MITF content were determined by Western blot. In the present study, we explore the anticancer effect of perphenazine and prochlorperazine in human melanotic (COLO829) and amelanotic (C32) melanoma cells concluding that prochlorperazine inhibits cell viability in a concentration-dependent manner, impairs motility, and decreases tyrosinase and MITF amounts. Moreover, the analyzed drugs decrease/increase MITF amount depending on the type of melanoma. We demonstrated that the decrease of MITF and tyrosinase protein induces motility inhibition of C32 cells, which suggests the ability of those drugs to restore cancer cell sensitivity to treatment. The ability of prochlorperazine to contain the spread of the amelanotic melanoma in vivo may be helpful in the development of a new and effective antimelanoma therapies.
\end{abstract}

Keywords Phenothiazine derivatives (perphenazine prochlorperazine) $\cdot$ Human melanotic (COLO829) and amelanotic (C32) melanoma $\cdot$ Viability $\cdot$ Motility $\cdot$ Tyrosinase $\cdot$ MITF

\section{Introduction}

Cutaneous melanoma is least common, yet accounts for only about $1 \%$ of skin cancers, and is the deadliest malignant tumor which begins in melanocytes of the skin (Garbe et al. 2016). According to the American Cancer Society in the year of 2018, it is estimated that in the USA, there will be 91,270 new cases of melanoma $(55,150$ for male, 36,120 for female) and 9320 deaths (5990 for male and 3330 for female) caused by the cancer (Siegel et al. 2018).

Michał Otręba

motreba@sum.edu.pl

1 Department of Pharmaceutical Chemistry, School of Pharmacy with the Division of Laboratory Medicine, Medical University of Silesia, Jagiellońska 4, 41-200 Sosnowiec, Poland

2 Bioanalytical Shared Resource Laboratory, Virginia Commonwealth University School of Pharmacy, Richmond, VA, USA
While melanomas are usually heavily pigmented, they can be also amelanotic, or devoid of pigment (Garbe et al. 2016). Thus, amelanotic melanoma is not only very difficult for clinical diagnosis (Chiaravalloti and Banki 2017) but also is more frequent and lethal than pigmented melanoma (Thomas et al. 2014). The primary treatment for most melanomas is surgery (Miller et al. 2016) or chemotherapy with dacarbazine and/or ipilimumab; additionally, a combination of vemurafenib and ipilimumab is recommended as first-line treatment depending on type of BRAF (B-Raf proto-oncogene) gene mutation of patients (Harries et al. 2016). Unfortunately, side effects such as nausea, vomiting, weight loss, decreased appetite, headache, fatigue, pyrexia, and insomnia may occur during melanoma chemotherapy (Drobek et al. 2017). Interestingly, perphenazine and prochlorperazine not only possess sedative, antiemetic (Motohashi et al. 2006; Sudeshna and Parimal 2010), and anticancer activity but also modify multidrug resistance (Girly et al. 2014; Jaszczyszyn et al. 2012). 
Melanogenesis is a multistep process of melanin pigment synthesis, which is regulated by the key enzyme tyrosinase, and a major transcription factor: microphthalmia-associated transcription factor (MTIF), which promotes differentiation, has a pro-survival role, and participates in cell cycle and metabolism regulation in melanocytes and melanoma (Kawakami and Fisher 2017; Otręba et al. 2012).

Previously, we determined cytotoxic activity of perphenazine and prochlorperazine towards human glioblastoma U87$\mathrm{MG}$ cells. The obtained $\mathrm{EC}_{50}$ values were related to their toxic concentrations in human plasma (Otręba and Buszman 2018). The current study is aimed at exploring the anticancer effect of perphenazine and prochlorperazine towards human melanotic (COLO829) and amelanotic (C32) melanoma cells. We conclude that perphenazine and prochlorperazine are an effective melanoma treatment based on the effect of the drugs on cellular viability, and motility, ability, as well as MITF and tyrosinase content.

\section{Materials and methods}

\section{Cell culture and reagents}

The human melanotic (COLO829) and human amelanotic (C32) cells were obtained from the ATCC (USA) and cultured in RPMI1640 (with L-glutamine) basal medium and DMEM basal medium at $37{ }^{\circ} \mathrm{C}$ in $5 \% \mathrm{CO}_{2}$, respectively. Both media were supplemented with FBS (10\%), neomycin $(10 \mu \mathrm{g} / \mathrm{mL})$, amphotericin B $(0.25 \mu \mathrm{g} / \mathrm{mL})$, and penicillin $\mathrm{G}(100 \mathrm{U} / \mathrm{mL})$. Perphenazine, prochlorperazine dimaleate, amphotericin B, and penicillin $\mathrm{G}$ were purchased from Sigma-Aldrich Inc. (USA). Cell Proliferation Reagent WST-1 was acquired from Roche GmbH (Germany). Neomycin sulfate was obtained from Amara (Poland). Trypsin/EDTA 0.25\%/0.02\% in PBS, fetal bovine serum (FBS) EU Professional heat-inactivated, growth medium DMEM with $4.5 \mathrm{~g} / \mathrm{L}$ glucose, L-glutamine and $3.7 \mathrm{~g} / \mathrm{L} \mathrm{NaHCO}_{3}$ as well as RPMI1640 with L-glutamine and $2.0 \mathrm{~g} / \mathrm{L} \mathrm{NaHCO}_{3}$ were obtained from PAN Biotech $\mathrm{GmbH}$ (Germany).

\section{Cell viability assay}

The viability of human melanoma COLO829 or C32 cell lines was evaluated by the colorimetric assay: WST-1 (4-(3-(4iodophenyl)-2-(4-nitrophenyl)-2H-5-tetrazolio)-1,3-benzene disulfonate) as previously described (Otręba and Buszman 2018) with slight modification. The melanoma cells were seeded in Falcon 96-well microplate (Corning, USA) at a cell density of 2500 cells/well and incubated in supplemented RPMI1640 or DMEM growth medium for $24 \mathrm{~h}$. Then, the medium was removed and cells were treated with perphenazine and prochlorperazine solutions in a concentration range from 1 to $10 \mu \mathrm{M}$. Stock solutions of drugs were prepared in water as solvent and dissolved in the bathing medium to obtain final concentrations of 1 or $10 \mu \mathrm{M}$. The absorbance of the samples was measured after $24 \mathrm{~h}$ incubation using a microplate reader Tecan Infinite M200 Pro (Tecan Group Ltd., Switzerland).

\section{Wound-healing assay}

The assay was performed according to the method described by Cao et al. (2014) and Justus et al. (2014) with slight modification to evaluate motility of the cells. In brief, $0.75 \times 10^{6}$ or $0.5 \times 10^{6}$ cells per well were plated in a $35-\mathrm{mm}$ cell culture dish (Sarsted, Germany) in a supplemented RPMI1640 or DMEM growth medium and incubated at $37{ }^{\circ} \mathrm{C}$ and $5 \%$ $\mathrm{CO}_{2}$ for $24 \mathrm{~h}$ to approximately $80-90 \%$ confluence. Then, the cells were scratched with a sterile $200-\mu$ l pipette tip across the dish to generate straight wound area, and then the medium and cell debris were carefully aspirated from the dish. After that, $2 \mathrm{ml}$ of supplemented growth medium, perphenazine, or prochlorperazine solutions were slowly added against the dish wall to cover the bottom of the dish to avoid detaching additional cells and incubated in the incubator for $24 \mathrm{~h}$. The wound areas were photographed at 6 time points, every $3 \mathrm{~h}(0,3,6,9$, 12 , and $24 \mathrm{~h}$ ) post-scratching using an inverted microscope Nikon TS100F (Nikon Corporation, Japan) equipped with a Canon EOS 450D digital camera (Canon Inc., Japan). Each time, three photos of each dish were taken and dishes were immediately placed in the incubator. All the photos were analyzed using ImageJ $1.51 \mathrm{j} 8$ software (National Institute of Health, USA) with the MRI wound-healing tool plug-in (Montpellier RIO Imaging, France) to measure the area of the wound. To analyze the time-dependent changes, the wound area of all the samples in $t_{0}$ were normalized to $100 \%$ for each assay and all of the $t_{3}-t_{24}$ samples were expressed as a percentage of relevant $t_{0}$ samples.

\section{Western blot analysis}

The MITF, tyrosinase protein, and $\beta$-actin amounts were determined by Western blot analysis according to the method described by Alao et al. (2014) with slight modification. Cells were treated with various concentrations of perphenazine, prochlorperazine, or medium for $24 \mathrm{~h}$. Then, cells were lysed directly in ice-cold Pierce RIPA buffer (Thermo Fischer Scientific, USA) and a Halt Protease Inhibitor (Thermo Fischer Scientific, USA) at $4{ }^{\circ} \mathrm{C}$ for $30 \mathrm{~min}$ with gentle agitation. Protein concentrations were analyzed by using a Pierce BCA Protein Assay Kit (Thermo Fischer Scientific, USA), and samples were stored at $-80{ }^{\circ} \mathrm{C}$. Samples were diluted in SDS-PAGE sample loading buffer (Advansta Inc., USA) containing $100 \mathrm{mM}$ dithiothreitol and boiled at $99{ }^{\circ} \mathrm{C}$ for $5 \mathrm{~min}$. Proteins were separated on 
$10 \%$ SDS-PAGE along with protein markers and transferred onto nitrocellulose membranes using a semi-dry blotting machine (Peqlab Ltd., UK). The membranes were blocked in blocking buffer [5\% (w/v) non-fat dried milk in TBST buffer $(0.05 \%(v / v)$ Tween 20/TBS)] for $1 \mathrm{~h}$ at room temperature. Proteins were detected by incubation with primary antibodies: Tyrosinase monoclonal antibody (T311) (MA5-14177, Thermo Fischer Scientific, USA), MITF (D5G7V) Rabbit mAB, and $\beta$-actin antibody (12590S, 4967S, Cell Signaling Technology, USA), at 1:1000 dilutions in blocking buffer overnight at $4{ }^{\circ} \mathrm{C}$. $\beta$ Actin was used as an internal control protein for loading normalization of the quantification analysis. The membranes were washed with TBST solution and then incubated with secondary peroxidase antibodies, goat anti-mouse IgG whole molecule; or goat anti-rabbit IgG whole molecule both diluted 1:2500 (Sigma-Aldrich, USA) at room temperature using the BlotCycler ${ }^{\mathrm{TM}}$ (Precision Biosystems, USA), according to the manufacturers' instructions. Immunoreactive bands were visualized using a Pierce ECL Western Blotting Substrate (Thermo Fischer Scientific, USA) following the manufacturer's protocol. The signals were detected with G:BOX XT4 (Syngen, UK) and expressed as the percentage of the controls.

\section{Statistical analysis}

In cellular viability and motility experiments, mean values of at least three separate experiments $(n=3)$ performed in triplicate \pm standard deviation (SD) were calculated. In Western blot analysis, mean values of at least three separate experiments $(n=3) \pm$ standard deviation (SD) were calculated. Statistical analysis was performed with one-way ANOVA (comparison samples vs control) with Dunnett's multiple comparison test and two-way ANOVA (the influence of cell line and time or drug concentration) followed by the Tukey post hoc test using GraphPad Prism 6.01 software. The significance level was established at the value of $p<0.05(*)$ or $p<0.01(* *)$.

\section{Results}

\section{Perphenazine and prochlorperazine decrease viability of melanoma cells}

Perphenazine in concentrations $2.5,5.0,7.5$, and $10.0 \mu \mathrm{M}$ reduced COLO829 cells viability by $26.0,52.0,82.6$, and $86.2 \%$ respectively, as well as in concentrations $1.0,2.5$, 5.0, 7.5, and $10.0 \mu \mathrm{M}$ lost $10.8,39.0,73.5,85.3$, and $90.9 \%$ of C32 cell viability, respectively (Fig. 1a). In the presence of prochlorperazine in concentrations 2.5, 5.0, 7.5, and $10.0 \mu \mathrm{M}$, the COLO829 and C32 melanoma
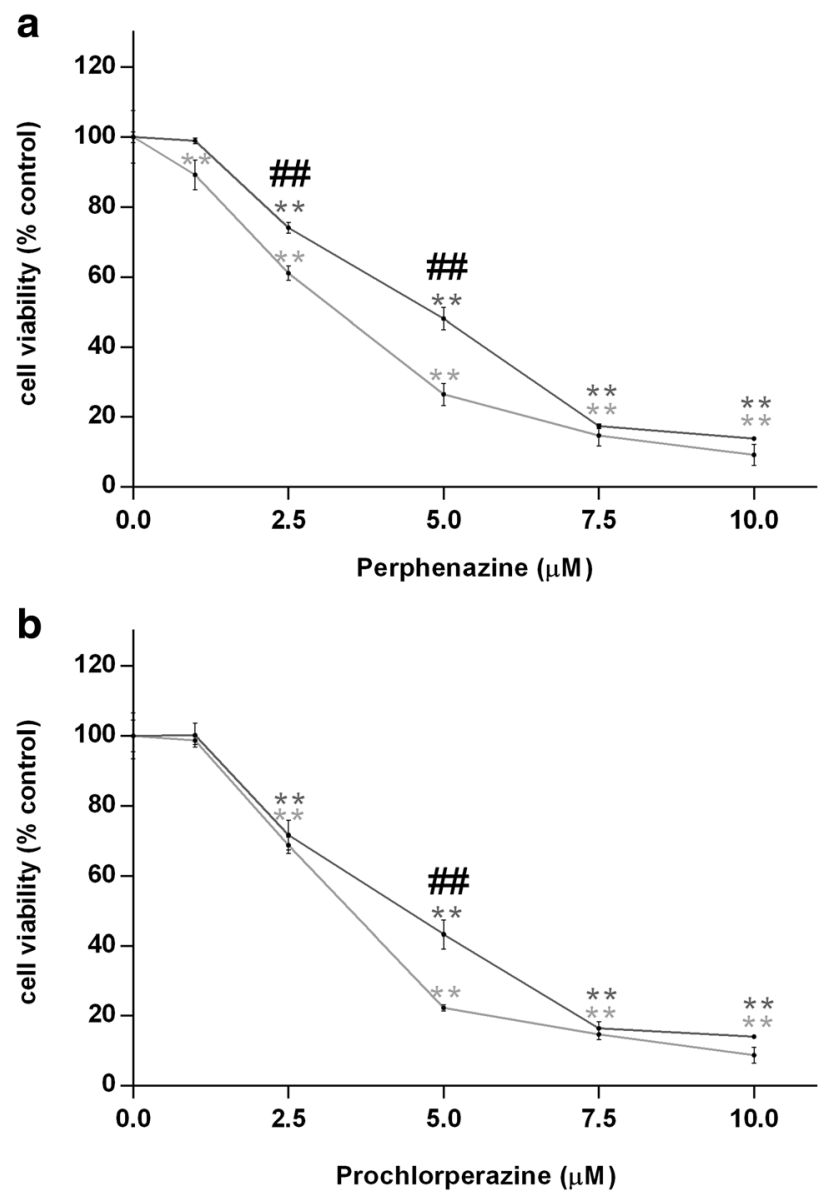

LEGEND:

- $\mathrm{C} 32$

- COLO829

** compared with control

\#\# compared COLO829 with C32

Fig. 1 The effect of perphenazine (a) and prochlorperazine (b) on human melanoma cell viability COLO829, and C32 cells were treated with various perphenazine and prochlorperazine $(10-100 \mu \mathrm{M})$ concentrations and examined by the WST-1 assay. Control samples contain cells in normal medium. Data are expressed as percent of the controls. Mean values $\pm \mathrm{SD}$ from three independent experiments $(n=3)$ performed in triplicate are presented ${ }^{* *} p<001$ vs the control samples, \#\#p<001 COLO829 vs C32 samples

viability decreased to $26.3,56.7,83.5$, and $86.0 \%$ as well as to $31.3,77.7,85.3$, and $91.2 \%$ after a $24-\mathrm{h}$ incubation, respectively (Fig. 1b). The influence of the lowest concentration of perphenazine $(1.0 \mu \mathrm{M})$ as well as perphenazine and prochlorperazine $(1.0 \mu \mathrm{M})$ on melanotic COLO829 and amelanotic $\mathrm{C} 32$ cell viability after $24-\mathrm{h}$ incubation was not significant. The $\mathrm{EC}_{50}$ values (the concentration of a drug that produces a loss in cell viability by $50 \%$ ) for perphenazine and prochlorperazine on COLO829 and C32 cells are shown in Table 1. 
Table 1 The $\mathrm{EC}_{50}$ values of perphenazine and prochlorperazine on COLO829 and C32 cells

\begin{tabular}{lll}
\hline Phenothiazine & $\mathrm{EC}_{50}(\mu \mathrm{M})$ COLO829 & $\mathrm{EC}_{50}(\mu \mathrm{M}) \mathrm{C} 32$ \\
\hline Perphenazine & $3.99 \pm 0.14$ & $2.62 \pm 0.12$ \\
Prochlorperazine & $3.76 \pm 0.14$ & $2.90 \pm 0.17$ \\
\hline
\end{tabular}

\section{Perphenazine and prochlorperazine impact on motility of human melanoma}

The effect of perphenazine and prochlorperazine on cell motility of COLO829 or C32 melanoma cells were examined using a quantitative wound-healing assay. After $6 \mathrm{~h}$ of treatment with $1 \mu \mathrm{M}$ prochlorperazine, the total wound area in melanotic melanoma cultures decreased by $30.4 \%$ in comparison to $t_{0}$. In case of 9,12 , and $24 \mathrm{~h}$ incubation, significant acceleration of wound closure and reduction of total wound area from $33.6 \%$ to $85.8 \%$ as well as from $48.2 \%$ to $92.8 \%$ and from $38.3 \%$ to $86.7 \%$ were observed for control and perphenazine ( 1 and $4 \mu \mathrm{M})$, respectively in comparison to $t_{0}$ group. For the same concentrations of prochlorperazine, acceleration of wound closure and reduction of total wound area from $46.2 \%$ to $86.8 \%$ and from $33.9 \%$ to $83.0 \%$ were also observed, respectively, in comparison to $t_{0}$ group (Fig. 2a and c). After $9 \mathrm{~h}$ in C32 cells in control we found the significant reduction of total wound area by $30.4 \%$ in comparison to $t_{0}$ group. After $12 \mathrm{~h}$ incubation, significant acceleration of wound closure and reduction of total wound area by $39.0 \%$, $38.1 \%, 29.0 \%$, and $32.1 \%$ were observed for control, perphenazine $(1$ and $3 \mu \mathrm{M})$, and prochlorperazine $(1 \mu \mathrm{M})$, respectively, in comparison to $t_{0}$ group. The inhibition of melanoma motility and delayed wound closure by $82.3 \%, 24.2 \%, 32.4 \%$, $41.6 \%, 34.5 \%$, and $50.3 \%$ were observed for 12 -h treatment amelanotic cells with prochlorperazine concentration of $3 \mu \mathrm{M}$ as well as for $24 \mathrm{~h}$ for control, perphenazine, and prochlorperazine ( 1 and $3 \mu \mathrm{M})$, respectively in comparison to $t_{0}$ group (Fig. 2b and d). Moreover, significant inhibition of melanoma motility was observed after $6,9,12$, and 24-h treatment amelanotic cells with prochlorperazine concentration of $3 \mu \mathrm{M}$ in comparison to control. In case of perphenazine, significant inhibition of C32 motility was observed only after 24-h treatment with concentration of $3 \mu \mathrm{M}$, in comparison to control.

\section{The effect of perphenazine and prochlorperazine on MITF and tyrosinase content in melanoma}

MITF and TYR proteins were expressed via western blot after a 24-h treatment of melanotic and amelanotic melanoma cells by different concentrations of perphenazine and prochlorperazine. In the case of COLO829 cells, an increase of MITF levels by 38.5 and $92.4 \%$ as well as 84.0 and $118.7 \%$ in comparison to control was observed after treatment of perphenazine (1 and $4 \mu \mathrm{M})$, and prochlorperazine ( 1 and $4 \mu \mathrm{M})$, respectively. The changes in tyrosinase level were not observed (Fig. 3a, c, and d). However, in the $\mathrm{C} 32$ cells treated with prochlorperazine in concentration, $3 \mu \mathrm{M}$ TYR levels reduced by $24 \%$, while after $24-\mathrm{h}$ treatment with prochlorperazine in concentrations, 1 and $3 \mu \mathrm{M}$ MITF level decreased by 17.9 and $25.2 \%$ compared with its control group, respectively (Fig. 3a and b).

\section{Discussion}

Our previous study has shown that perphenazine and prochlorperazine induce a concentration-dependent loss in human glioblastoma U87-MG viability; additionally, obtained $\mathrm{EC}_{50}$ values for the drugs (0.98 and $0.97 \mu \mathrm{M}$, respectively) correlate with their toxic human plasma concentrations (Otręba and Buszman 2018), which are from 0.05 to $1 \mu \mathrm{g} / \mathrm{ml}$ (i.e., $0.12-2.47 \mu \mathrm{M}$ ) for perphenazine and from 0.2 to $1 \mu \mathrm{g} / \mathrm{ml}$ (i.e., $0.33-1.65 \mu \mathrm{M}$ ) for prochlorperazine (Schulz and Schmoldt 2003; Winek et al. 2001). In the present study, we have demonstrated that prochlorperazine can reduce cell viability, impair motility, and decrease tyrosinase and MITF content in human amelanotic melanoma. In addition, we observed significantly increased level of MITF protein, reduced cytotoxicity, and motility in human melanotic melanoma after perphenazine and prochlorperazine treatment.

Concentration-dependent decrease of different melanoma cell viability after phenothiazine derivative treatment (chlorpromazine (Gil-Ad et al. 2006, Parsons and Allen 1986), fluphenazine (Gil-Ad et al. 2006, Kuzu et al. 2017), perphenazine (Gil-Ad et al. 2006, Kuzu et al. 2017), thioridazine (GilAd et al. 2006), and trifluoperazine (Kuzu et al. 2017)) is frequently observed as well as higher sensitivity of amelanotic melanoma (MM96L) in comparison to melanotic (MM96E) after chlorpromazine treatment was also observed (Parsons and Allen 1986). In accordance with these reports, we find concentration-dependent loss in both human melanoma cells viability treated with perphenazine and prochlorperazine. Furthermore, in the present study, the obtained $\mathrm{EC}_{50}$ values suggest that the analyzed drugs are more cytotoxic to amelanotic melanoma than melanotic cells as well as that the orders of the drugs' cytotoxicity towards COLO829 and C32 cells are prochlorperazine $\geq$ perphenazine and perphenazine $\geq$ prochlorperazine, respectively.

Noteworthy, the observed in literature $\mathrm{IC}_{50}$ (the drug concentration causing $50 \%$ inhibition of the desired activity) values for perphenazine (11.6 $\mu \mathrm{M}$ (Gil-Ad et al. 2006) 9.7, 9.3, 10.9, 17.9, and $23.2 \mu \mathrm{M}$ (Kuzu et al. 2017) depending on used cell line) are about 3-7.5 $\times$ higher than ours indicating that the obtained $\mathrm{EC}_{50}$ values for amelanotic $\mathrm{C} 32$ cells are much closer to the toxic human plasma concentrations. In case of prochlorperazine, the lethal human plasma concentration is 


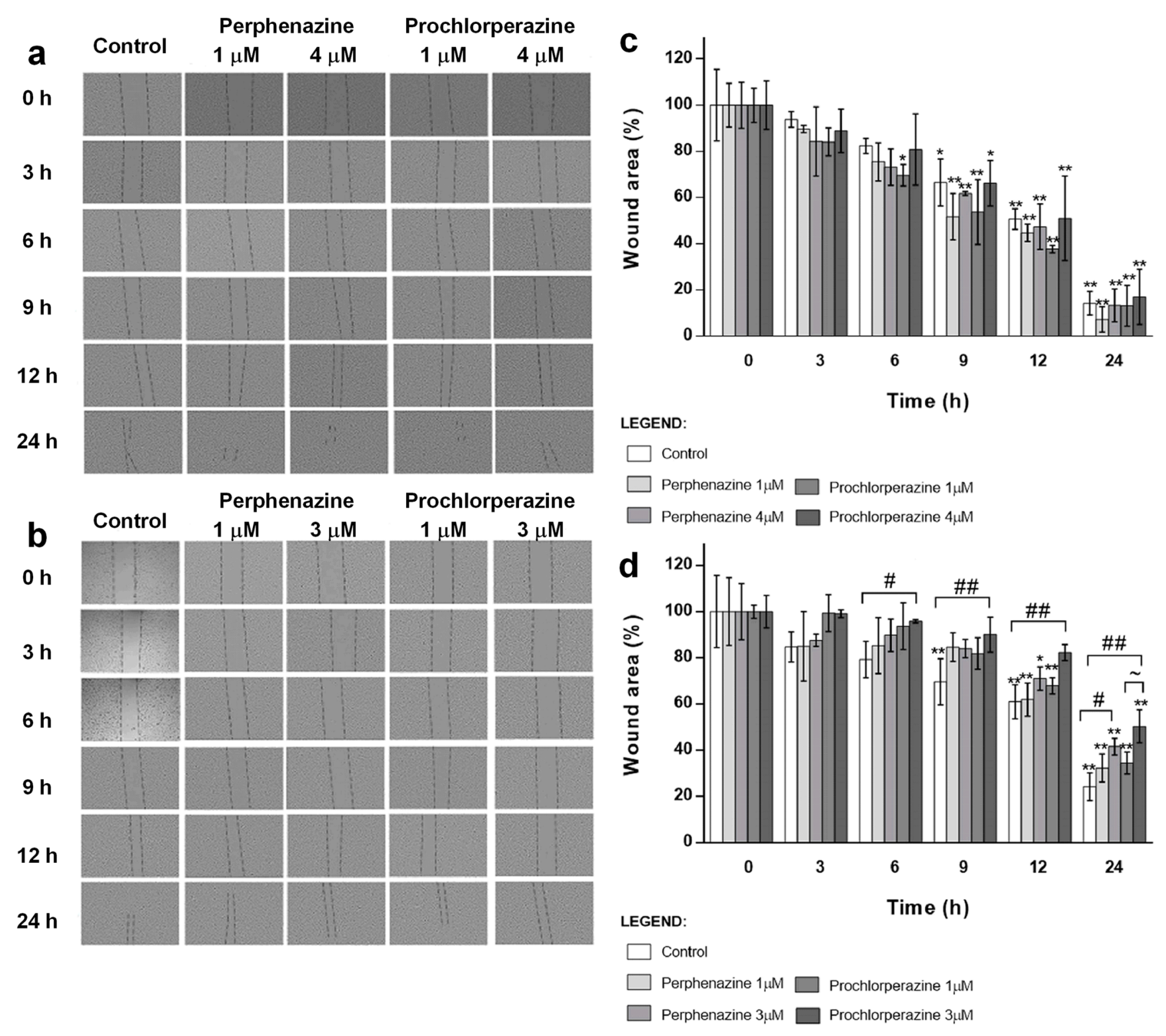

Fig. 2 The impact of perphenazine and prochlorperazine on melanoma cell motility. In vitro wound-healing assay on COLO829 (a), and C32 (b) COLO829 cells were incubated for $24 \mathrm{~h}$ with perphenazine or prochlorperazine in concentrations $(1$ and $4 \mu \mathrm{M})$, while C32 cells were incubated for $24 \mathrm{~h}$ with perphenazine or prochlorperazine in concentrations $(1$ and $3 \mu \mathrm{M})$. Cells were photographed after $0,3,6,9,12$, and $24 \mathrm{~h}$ post-scratching by Nikon TF100 inverted microscope $\times 4$ magnification.

$5 \mu \mathrm{g} / \mathrm{ml}$ (i.e., $8.25 \mu \mathrm{M}$ ) (Schulz and Schmoldt 2003; Winek et al. 2001). Remarkably, our previous study showed that perphenazine and prochlorperazine $\mathrm{EC}_{50}$ values for normal human epidermal melanocytes neonatal darkly pigmented (HEMn-DP) were 2.76 and $18.49 \mu \mathrm{M}$, respectively (Otręba et al. 2016; Otręba et al. 2017). It suggests that prochlorperazine can be much safer than perphenazine during anticancer therapy, in comparison to the present results for melanotic COLO829 cells-perphenazine is more cytotoxic, while prochlorperazine
Representative cell images from each group at the indicated time points are shown. Wound area in COLO829 (c) and C32 (d) cells expressed as a percentage of control. Mean values \pm SD from three independent experiments $(n=3)$ performed in triplicate are presented $* p<005 * *<001$ vs the $t_{0}$ group, $\# p<005 \# \# p<001$ between control, perphenazine, and prochlorperazine in the same time point, $\sim p<005$ between the same drug concentration in the same time point is about $5 \times$ less toxic towards HEMn-DP cells. The benefits of use $\mathrm{EC}_{50}$ values in potential melanotic melanoma treatment are lower cytotoxicity in comparison to the normal melanocytes as well as the concentration of drugs related to the concentrations detected in human plasma (close to the toxic plasma concentrations), which is interesting, since the anticancer activity of phenothiazine derivatives is usually observed in a range of lethal human plasma concentration. On the other hand, the possibility of undesirable side effect occurrence during the therapy is much 


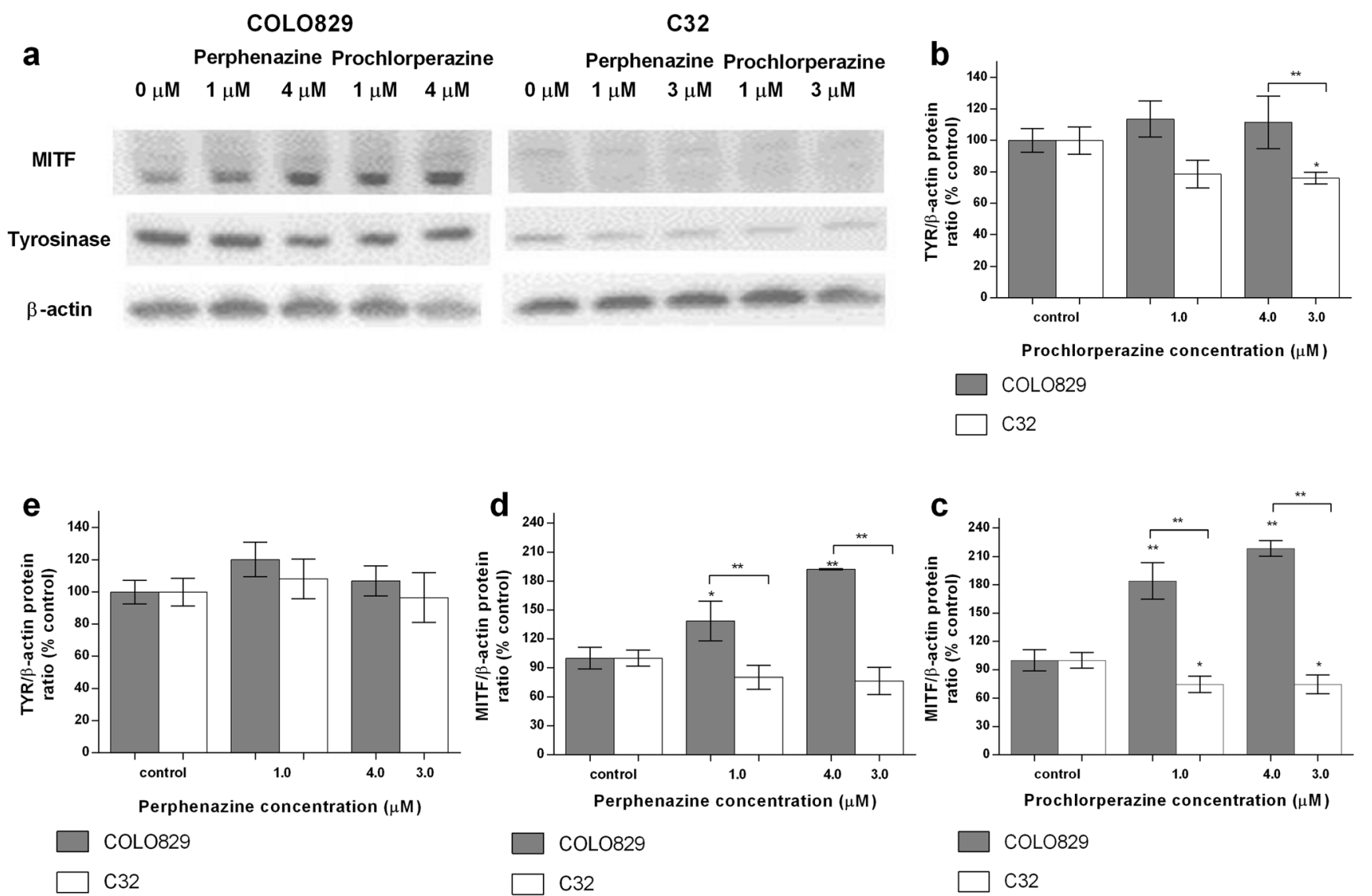

Fig. 3 Western blot analysis and a correlated graph of the relative amount of selected proteins including loading controls a blots of tyrosinase, MITF and $\beta$-actin, as well as their relative amounts: $\mathbf{b}$ tyrosinase in COLO829 and C32 after 24-h prochlorperazine treatment, $\mathbf{c}$ MITF in COLO829 and C32 after 24-h prochlorperazine treatment, $\mathbf{d}$ tyrosinase in COLO829 and C32 after 24-h perphenazine treatment, e MITF in

COLO829 and C32 after 24-h perphenazine treatment, expressed as percent of control. Perphenazine and prochlorperazine were used in the same concentrations as in the wound-healing assay. Mean values \pm SD from three independent experiments $(n=3)$ are presented $* p<005, * * p<001$ vs the control samples or COLO829 vs C32 samples

higher, since the drug concentration is not related to the therapeutic plasma concentration range. Thus, much more research is still needed to confirm the effectiveness of phenothiazine derivatives in melanoma treatment.

We also evaluated the effect of perphenazine and prochlorperazine on the motility of both human melanoma cell lines since a major problem of melanoma is metastasis to lungs and central nervous system (Batus et al. 2013). Our study showed significant differences between both melanotic and amelanotic cell line for $1 \mu \mathrm{M}$ concentration of perphenazine after $9 \mathrm{~h}$ $(p<0.01)$ and prochlorperazine after 9 and $12 \mathrm{~h}(p<0.05$, $p<0.01$, respectively) as well as for highest concentrations of perphenazine after $24 \mathrm{~h}(p<0.05)$ and prochlorperazine after 12 and $24 \mathrm{~h}(p<0.01, p<0.01$, respectively). It suggests that $24-\mathrm{h}$ perphenazine and prochlorperazine in the concentration of $3 \mu \mathrm{M}$ treatment exert significant anti-metastatic effects on human amelanotic C32 cells. Moreover, the significant difference was also observed after $6,9,12$, and $24 \mathrm{~h}$ in the same cell line for prochlorperazine in the highest concentration in comparison to the control, suggesting that the drug could help to contain the spread of the amelanotic melanoma in vivo.

The microphthalmia-associated transcription factor (MITF) is considered as an important growth and survival factor (Wellbrock and Arozarena 2015). The level of MITF is very important for melanoma, since medium levels of MITF expression were found in melanoma patients with high mortality (Agnarsdóttir et al. 2012), a low activity is related to stem cell-like or invasive potential, while high levels regulate either differentiation or proliferation (Carreira et al. 2006; Hartman and Czyz 2015). Importantly, decrease of MITF levels is frequently observed in different melanoma cells (Fane et al. 2017; Simmons et al. 2017; Vlčková et al. 2018), while the depletion of MITF significantly reduced the migration of melanoma cells (Simmons et al. 2017). Noteworthy, all the results suggest that the role of MITF in melanoma cell migration depends on the used cell line. Consistent with this statement, we showed a significant dose-dependent increase of MITF level together with no impact on motility of COLO829 cells treated with perphenazine and prochlorperazine. In contrast, the significant decrease of MITF level and motility was observed only after prochlorperazine treatment in $\mathrm{C} 32$ cells, which is considered to be more invasive. 
MITF is also essential for melanogenesis process by the transcription regulation of tyrosinase (TYR), tyrosinase-related protein 1 (TRP1), and dopachrome tautomerase (DCT) (Vachtenheim 2017). Since melanin content may be related to viability and motility of melanoma as well as being crucial for the effectiveness of anti-melanotic therapy, we decided to measure amount of the tyrosinase. It is possible, since the pigment is able to reversibly bind metal ions, organic amines, cyclic compounds, and drugs (Rok et al. 2012), e.g., phenothiazine derivatives (Otręba et al. 2017), and are retained in cells for long periods leading to protect the cells or causing toxicity slowly release accumulated compounds from depot (Rok et al. 2012). Thus, a modulation of tyrosinase may restore cancer cell sensitivity to chemotherapy by the depletion of pigment amount and increasing the concentration of unbound drug (Buitrago et al. 2016). An important point is the fact that TYR expression is observed in nevi and in $80-90 \%$ of primary and metastatic melanomas, which makes it a useful diagnostic marker (Pitcovski et al. 2017) as well as that decrease of tyrosinase amount is frequently observed and correlates with the MITF level (Hashemi-Shahri et al. 2018, Lee et al. 2015). In the present study, we observed a significant decrease of tyrosinase in C 32 cells after prochlorperazine treatment only in concentration of $3 \mu \mathrm{M}$. This might be an effect of stronger inhibition of MITF protein and suggests that the decrease of TYR level is caused by a decline of MITF amount. Thus, our finding may confirm the role of melanin pigment in effectiveness of prochlorperazine in amelanotic melanoma therapy, since in $\mathrm{C} 32$ cells we observed significant decrease of tyrosinase and MITF amount as well as impair motility and viability of the cells. However, our study has a major limitation - no experiments evaluating the receptor(s) involved in the observed effects. Therefore, analysis of the role of tested drugs on serotonin (5-HT) and dopamine (D) receptors would provide reliable information on antimelanoma activity.

Interestingly, the potential anticancer activity of phenothiazine derivatives may be confirmed in the near future, since according to the National Cancer Institute (NCI), two clinical trials use phenothiazine derivatives in anticancer therapy: Haloperidol with or without Chlorpromazine in Treating Delirium in Patients with Advanced, Metastatic, or Recurrent Cancer-Phase II/III, Clinicaltrials.gov ID: NCT03021486; Study of Fluphenazine in Relapsed or Relapsed-andRefractory Multiple Myeloma-Phase I, Clinicaltrials.gov ID: NCT00821301 (NCI, Accessed 19 April 2019).

Data presented here indicates that perphenazine and prochlorperazine possess an anticancer activity in vitro and significantly decrease viability in melanotic and amelanotic cells. We showed the decrease of tyrosinase and MITF amount as well as impairment of motility in C32 cell line. These results highlight that prochlorperazine is the most effective towards amelanotic cell line and could be a promising strategy for treating amelanotic melanoma. Moreover, prochlorperazine possess antiemetic activity and modifies multidrug resistance which is necessary in anticancer therapy. Thus, we considered that the drug may have a potential for the development of new and effective amelanotic melanoma therapy. To confirm the effectiveness of prochlorperazine in melanoma treatment, more research is still needed, such as 5-HT and/or D receptor's role, cell invasion and migration by the Transwell assays as well as apoptosis.

Author contribution MO conceived and designed the research, conducted the experiments, and analyzed data. MO and MP conducted viability experiments and analyzed the data. MO and JW wrote the manuscript.

All the authors read and approved the manuscript.

Funding This study was founded by the Medical University of Silesia in Katowice, Poland (Grant Nos. KNW-2-005-N/7/K, KNW-2-015/N/8/K). Professor Ewa Buszman partially supported this work from grant No. KNW-1-034/K/7/O

\section{Compliance with ethical standards}

Conflict of interests The authors declare that they have no conflict of interest.

Ethical approval This article does not contain any studies with human participants or animals performed by any of the authors.

Open Access This article is distributed under the terms of the Creative Commons Attribution 4.0 International License (http:// creativecommons.org/licenses/by/4.0/), which permits unrestricted use, distribution, and reproduction in any medium, provided you give appropriate credit to the original author(s) and the source, provide a link to the Creative Commons license, and indicate if changes were made.

\section{References}

Agnarsdóttir M, Ponten F, Garmo H, Wagenius G, Mucci L, Magnusson K, Holmberg L, Eaker-Fält S (2012) MITF expression in cutaneous malignant melanoma. J Mol Biomark Diagn 3:1-7

Alao JP, Michlikova S, Dinér P, Grøtli M, Sunnerhagen P (2014) Selective inhibition of RET mediated cell proliferation in vitro by the kinase inhibitor SPP86. BMC Cancer 14:853

Batus M, Waheed S, Ruby C, Petersen L, Bines SD, Kaufman HL (2013) Optimal management of metastatic melanoma: current strategies and future directions. Am J Clin Dermatol 14:179-194

Buitrago E, Hardré R, Haudecoeur R, Jamet H, Belle C, Boumendjel A, Bubacco L, Réglier M (2016) Are human tyrosinase and related proteins suitable targets for melanoma therapy? Curr Top Med Chem 16:3033-3047

Cao HH, Tse AKW, Kwan HY, Yu H, Cheng CY, Su T, Fong WF, Yu Z (2014) Quercetin exerts anti-melanoma activities and inhibits STAT3 signaling. Biochem Pharmacol 87:424-434

Carreira S, Goodall J, Denat L, Rodriguez M, Nuciforo P, Hoek KS, Testori A, Larue L, Goding CR (2006) Mitf regulation of Dia1 controls melanoma proliferation and invasiveness. Genes Dev 20: 3426-3439

Chiaravalloti A, Banki A (2017) An elusive amelanotic melanoma and review of dermoscopic findings. J Drugs Dermatol 16:1164-1165 
Drobek HH, Bergler-Czop BS, Miziołek B (2017) From chemotherapy to oncoviruses - modern methods of treatment in metastatic melanoma. Dermatol Rev/Przegl Dermatol 104:396-410

Fane ME, Chhabra Y, Hollingsworth DEJ, Simmons JL, Spoerri L, Oh TG, Chauhan J, Chin T, Harris L, Harvey TJ, Muscat GEO, Goding CR, Sturm RA, Haass NK, Boyle GM, Piper M, Smith AG (2017) NFIB mediates BRN2 driven melanoma cell migration and invasion through regulation of EZH2 and MITF. EBioMedicine. 16:63-75

Garbe C, Peris K, Hauschild A, Saiag P, Middleton M, Bastholt L, Grob JJ, Malvehy J, Newton-Bishop J, Stratigos AJ, Pehamberger H, Eggermont AM, European Dermatology Forum (EDF); European Association of Dermato-Oncology (EADO); European Organisation for Research and Treatment of Cancer (EORTC) (2016) Diagnosis and treatment of melanoma. European consensus-based interdisciplinary guideline - update 2016. Eur J Cancer 63:201-217

Gil-Ad I, Shtaif B, Levkovitz Y, Nordenberg J, Taler M, Korov I, Weizman A (2006) Phenothiazines induce apoptosis in a B16 mouse melanoma cell line and attenuate in vivo melanoma tumor growth. Oncol Rep 15:107-112

Girly V, Baldwin MV, Jini J, Meena C, Bhat AR, Kumar KK (2014) A review on biological activities of thiazine derivatives. Int P Pharm Chem Biol Sci 3:341-348

Harries M, Malvehy J, Lebbe C, Heron L, Amelio J, Szabo Z, Schadendorf D (2016) Treatment patterns of advanced malignant melanoma (stage III-IV) - a review of current standards in Europe. Eur J Cancer 60:179-189

Hartman ML, Czyz M (2015) MITF in melanoma: mechanisms behind its expression and activity. Cell Mol Life Sci 72:1249-1260

Hashemi-Shahri SH, Golshan A, Mohajeri SA, Baharara J, Amini E, Salek F, Sahebkar A, Tayarani-Najaran Z (2018) ROS-scavenging and anti-tyrosinase properties of crocetin on B16F10 murine melanoma cells. Anti Cancer Agents Med Chem 18:1064-1069

Jaszczyszyn A, Gąsiorowski K, Świątek P, Malinka W, Cieślik-Boczula K, Petrus J, Czarnik-Matusewicz B (2012) Chemical structure of phenothiazines and their biological activity. Pharmacol Rep 64:1623

Justus CR, Leffler N, Ruiz-Echevarria M, Yang LV (2014) In vitro cell migration and invasion assays. J Vis Exp 88:1-8. https://doi.org/10. $3791 / 51046$

Kawakami A, Fisher DE (2017) The master role of microphthalmiaassociated transcription factor in melanocyte and melanoma biology. Lab Investig 97:649-656

Kuzu OF, Gowda R, Noory MA, Robertson GP (2017) Modulating cancer cell survival by targeting intracellular cholesterol transport. Br J Cancer 117:513-524

Lee SM, Chen YS, Lin CC, Chen KH (2015) Hair dyes resorcinol and lawsone reduce production of melanin in melanoma cells by tyrosinase activity inhibition and decreasing tyrosinase and microphthalmia-associated transcription factor (MITF) expression. Int J Mol Sci 16:1495-1508

Miller KD, Siegel RL, Lin CC, Mariotto AB, Kramer JL, Rowland JH, Stein KD, Alteri R, Jemal A (2016) Cancer treatment and survivorship statistics, 2016. CA Cancer J Clin 66:271-289

Motohashi N, Kawase M, Satoh K, Sakagami H (2006) Cytotoxic potential of phenothiazines. Curr Drug Targets 7:1055-1066

National Cancer Institute (NCI), NCI-supported clinical trials https:// www.cancer.gov/. Accessed 19 Apr 2019
Otręba M, Buszman E (2018) Perphenazine and prochlorperazine induce concentration-dependent loss in human glioblastoma cells viability. Pharmazie. 73:19-21

Otręba M, Rok J, Buszman E, Wrześniok D (2012) Regulation of melanogenesis: the role of cAMP and MITF. Postepy Hig Med Dosw 66: 33-40

Otręba M, Wrześniok D, Beberok A, Rok J, Buszman E (2016) Fluphenazine and perphenazine impact on melanogenesis and antioxidant enzymes activity in normal human melanocytes. Acta Pol Pharm Drug Res 73:903-911

Otręba M, Wrześniok D, Rok J, Beberok A, Buszman E (2017) Prochlorperazine interaction with melanin and melanocytes. Pharmazie. 72:171-176

Parsons PG, Allen BJ (1986) Accumulation of chlorpromazine and thiouracil by human melanoma cells in culture. Aust J Exp Biol Med Sci 64:517-526

Pitcovski J, Shahar E, Aizenshtein E, Gorodetsky R (2017) Melanoma antigens and related immunological markers. Crit Rev Oncol Hematol 115:36-49

Rok J, Otręba M, Buszman E, Wrześniok D (2012) Melanin - from melanocyte to keratinocyte, that is how melanin is transported within the skin. Ann Acad Med Siles 66:60-66

Schulz M, Schmoldt A (2003) Therapeutic and toxic blood concentrations of more than 800 drugs and other xenobiotics. Pharmazie. 58: 447-474

Siegel RL, Miller KD, Jemal A (2018) Cancer statistics, 2018. CA Cancer $\mathrm{J}$ Clin 68:7-30

Simmons JL, Pierce CJ, Al-Ejeh F, Boyle GM (2017) MITF and BRN2 contribute to metastatic growth after dissemination of melanoma. Sci Rep 7:10909. https://doi.org/10.1038/s41598-017-11366-y

Sudeshna G, Parimal K (2010) Multiple non-psychiatric effects of phenothiazines: a review. Eur J Pharmacol 648:6-14

Thomas NE, Kricker A, Waxweiler WT, Dillon PM, Busam KJ, From L, Groben PA, Armstrong BK, Anton-Culver H, Gruber SB, Marrett LD, Gallagher RP, Zanetti R, Rosso S, Dwyer T, Venn A, Kanetsky PA, Orlow I, Paine S, Ollila DW, Reiner AS, Luo L, Hao H, Frank JS, Begg CB, Berwick M (2014) Comparison of clinicopathologic features and survival of histopathologically amelanotic and pigmented melanomas a population-based study. JAMA Dermatol 150:1306-1314

Vachtenheim J (2017) The many roles of MITF in melanoma. Single Cell Biol 6:162. https://doi.org/10.4172/2168-9431.1000162

Vlčková K, Vachtenheim J, Réda J, Horák P, Ondrušová L (2018) Inducibly decreased MITF levels do not affect proliferation and phenotype switching but reduce differentiation of melanoma cells. J Cell Mol Med 22:2240-2251. https://doi.org/10.1111/jcmm. 13506

Wellbrock C, Arozarena I (2015) Microphthalmia-associated transcription factor in melanoma development and MAP-kinase pathway targeted therapy. Pigment Cell Melanoma Res 28:390-406

Winek CL, Wahba WW, Winek CL Jr, Balzer TW (2001) Drug and chemical blood-level data 2001. Forensic Sci Int 122:107-123

Publisher's note Springer Nature remains neutral with regard to jurisdictional claims in published maps and institutional affiliations. 